\title{
The hardest thing to see is what is in front of your eyes - quo vadis placebo analgesia?
}

\section{Rupert Conrad}

Department of Psychosomatic Medicine and Psychotherapy, University of Bonn, Bonn, Germany

Correspondence: Rupert Conrad Department of Psychosomatic Medicine and Psychotherapy, University of Bonn, Sigmund-Freud-Straße 25, D-53I05 Bonn, Germany

Tel +49228287I 6299

Email Rupert.Conrad@ukb.uni-bonn.de

\author{
This article was published in the following Dove Press journal: \\ Journal of Pain Research \\ 14 October 2016 \\ Number of times this article has been viewed
}

Recent years have seen a huge increase in knowledge about the phenomenon of placebo analgesia. As such, we are able to state with confidence that placebo analgesia exists and exhibits clinically relevant effects, ${ }^{1-4}$ even though the relative sizes of these effects display a large variation.

The underlying mechanism has been described in a seminal definition by Brody: "a change in a patient's illness attributable to the symbolic import of a treatment rather than a specific pharmacologic or physiologic property". ${ }^{5}$ This definition highlights the importance of the mind-body interaction in the placebo effect, as well as the powerful influence of meaningful symbols in the healing ritual that goes beyond a merely positivistic approach. Currently, the underlying psychological and neurobiological mechanisms are recognizable in outline, with expectation and conditioning believed to lie at the heart of placebo response. ${ }^{6}$ High levels of endogenous opioids and cannabinoids, and low levels of cholecystokinin, are implicated as the principal pharmacologic mediators of placebo analgesia. ${ }^{4}$ The dorsolateral prefrontal cortex initiates the placebo analgesic response $\mathrm{e}^{7}$ leading to increased activity within the descending pain-modulatory pathway. ${ }^{8,9}$ The activity of regions such as the dorsal horn of the spinal cord, the thalamus, the insula, and the somatosensory cortex is decreased by the placebo, indicating a reduction in nociceptive transmission in the pain pathways..$^{7-9}$

Against the background of these groundbreaking findings, it is surprising that the conscious promotion of the use of placebo analgesia for medical training and in clinical practice remains uncommon. In my view, there are several reasons for this, as follows.

The first such reason is historical. One of the earliest usages of the word "placebo" refers to 14th century funeral hymns conveying the message "De mortuis nihil nisi bene" ${ }^{4}$ This explains the close association of the word placebo to hypocrisy, and when the term was introduced into medicine in the 18th century, placebo treatment became a synonym for pseudo-healing. Even though alternative terms such as meaning-response ${ }^{10}$ have been proposed, modern medicine retains this term and its derogatory connotations.

Secondly, the medical use of placebos has always entailed significant ethical concerns. ${ }^{11}$ Placebo interventions have been equated with the deliberate deception of the patient, which is incompatible with a doctor-patient relationship based on trust and honesty. However, at this point of the scientific debate, this argument requires some reexamination. Since the beginning of modern medicine, the Hippocratic Oath has been seen as the basis of a salutary doctor-patient relationship: "I will use treatment to 
help the sick according to my ability and judgment, but never with a view to injury and wrong-doing". ${ }^{12}$ Simply stated, the doctors should do everything in their power to cure the patients and not bring them any harm. A deception with the sole intention to heal the patients hence does not contradict this medical commandment, and may even be compatible to the highest ethical standards, as defined by Kant's categorical imperative: "act only in such a way that you can will that the maxim of your actions should become a universal law", ${ }^{13}$

The question then arises: what is the patients' perspective? In a survey of the attitudes toward the use of placebos involving 853 US patients with chronic health problems, $76 \%$ of respondents deemed that it was acceptable for a doctor to recommend a placebo if he thought that it would benefit and not harm the patient, while $50 \%$ considered it acceptable in instances where the doctor is uncertain of its benefit. ${ }^{14}$ Another ethical question may equally be posed: is a placebo intervention necessarily deceptive? Clearly, this is a matter of formulation. If a doctor suggests to his patient that a drug is likely to be beneficial, even though it has no pharmacological activity, this would be only deceptive if the doctor himself does not believe in the drug's effectiveness. If the doctor is convinced of the effectiveness of placebo analgesia, he may even explicitly recommend it to patients. Thus, Kaptchuk et al ${ }^{15}$ were able to prove the effectiveness of placebos in patients with chronic pain due to irritable bowel syndrome when such placebos were given transparently and accompanied by information about the placebo effect.

The third argument is associated with the development of modern medicine. In Western industrialized countries, this development is based on a tradition that can be traced back to Descartes and the Age of Enlightenment. Descartes' conception of the existence of two mutually differentiated substances - res extensa and res cogitans, mind and matter - has been the basis of the progressive fragmentation of medicine into smaller and smaller areas of expertise. ${ }^{4,6}$ However, the incredible growth of knowledge resulting from this specialization has seen a resultant difficulty in maintaining the balance between analysis and synthesis in medical treatment, a consequence of which may be that painplagued individuals become lost in a mire of sophisticated medical findings. Increasing specialization goes hand in hand with the appreciation of specific healing mechanisms and a disregard of more general healing principles, such as the placebo response. It may be assumed that this notion played a crucial role when William Cullen introduced the negatively connoted term "placebo" into medicine in the 18th century. ${ }^{4}$ This assessment also lies at the heart of ran- domized placebo-controlled design - the core methodology of evidence-based medicine. And here we come full circle. Against this background, the doctor is under the impression that he deceives the patient, as only the medical intervention proven to be more effective than the placebo is considered the true remedy.

A fourth and final argument is the increasing economization of medicine in general, and pain medicine in particular, driven by the sole concern of cost containment and profitability. ${ }^{16,17}$ The empathic and time-consuming doctor-patient communication so essential to the symbolic import of treatment is no longer a fundamental part of the art of medical healing; rather, it is reduced to the status of a problematic cost factor. In both Germany and the US, for instance, there is an overutilization of interventional procedures and spine surgery, which is at least partially attributable to dubious incentives from industry and the health care system. ${ }^{16-18}$ Complete transparency is a necessary requirement to disclose these entangled relationships. ${ }^{19,20}$ While somewhat controversial, the Physician Payment Sunshine Act in the US is a first step in this direction. ${ }^{21}$ However, German legislation still lags behind. In 2013, the Association of Voluntary Self-Control of the Pharmaceutical Industry (FSA) in Germany adopted a code of transparency for interaction with health care professionals, according to which all future payments in kind by the pharmaceutical industry to health care professionals and organizations in this field shall be made public. However, only about $30 \%$ of doctors agreed to be named personally as beneficiaries of pharmaceutical industries represented by the FSA in $2015 .{ }^{22}$ It remains to be seen whether these are merely clandestine attempts to avoid strict legal action, or whether they will lead to real transparency. Nevertheless, the mechanisms of capitalism pose a severe ethical threat to pain medicine if the patient is no longer treated as an end in itself but as a means to maximize profits. ${ }^{13}$

Against this background, pain medicine should seek to question how the untapped potential of placebo analgesia may be better utilized in the future. The following healing ritual factors can be drawn from an analysis of the psychosocial context: the setting, the doctor's personality, the patient's personality, the type of intervention, and the interaction between these factors. ${ }^{23}$ Each of these factors presents specific challenges for pain medicine and research, which are examined in more detail as follows.

The first question to consider is: what is the best therapeutic setting for placebo analgesia in terms of time and place? Healing rituals require sufficient time for a doctor-patient relationship to instill positive expectations in the patient. ${ }^{4}$ 
The location should be somewhere that makes it possible to perceive positively charged symbols and their meaning. In ancient Greek medicine, healing temples dedicated to Asklepios provided carefully designed spaces for spiritual and physical healing. A comparison of the Asklepion in Epidauros and the contemporary design of an aseptic hospital room makes evident the wide range of places of healing and their possible potency. In a seminal study, Ulrich ${ }^{24}$ showed that a hospital window view of trees could influence surgical patients' use of analgesics and recovery. Compared with a wall-view group, these patients had shorter postoperative hospital stays, took fewer moderate and strong analgesic doses, and had slightly lower scores for minor postsurgical complications. A more recent study showed that the postoperative exposure of patients who had undergone spinal surgery to increased amounts of natural sunlight during their hospital recovery period resulted in decreased stress, pain, and analgesic medication use. ${ }^{25}$ Health care architecture should be aware of the healing impact of (natural) symbols an area in which research and architectural implementation is still in its infancy.

Second is the question of the medical self-image. The relationship between doctor and patient is at the center of the healing ritual. Shapiro and Shapiro ${ }^{26}$ have emphasized the relevance of the placebo response to the doctor's authenticity, empathy, and unconditionally positive regard for the patient. Equally, several studies have showed a positive effect on pain reduction in situations where the doctor is perceived as warm and empathetic. ${ }^{27-29}$ Medical communication is both verbal and nonverbal, with nonverbal communication having a much greater potency as its influence is less deliberate. ${ }^{30}$ The credibility of the medical message depends on the authenticity of the doctor, which is derived from the congruence of verbal and nonverbal signals. ${ }^{30}$ This relationship is insufficiently emphasized in medical training, and as a result, there is a lack of awareness surrounding it. A brief example may illustrate the problem. If a chronic pain patient undergoing long and frustrating therapy triggers anger in the doctor, but the doctor himself is not aware of the feeling, this can severely complicate treatment. The patient senses the nonverbal signals and feels rejected, resulting in a possible loss of faith in the treatment and its ultimate discontinuation. Conversely, if the doctor is in a position to reflect this feeling professionally and incorporate it productively in the doctor-patient communication, this may lead to positive expectations being developed. Thus, the doctor's voice, facial expressions, and gestures become positively or negatively charged symbols for the patient, turning the healing ritual into a placebo or nocebo. However, few components in formal medical training - in either direct curricular instruction or physician role modeling - focus on the emotional lives of students or junior doctors. ${ }^{31}$ There is currently still a focus on the requirement for doctors to ignore, distance, and detach themselves from emotions as a means to retain professional control. Obviously, this runs contrary to genuine expression and authentic communication. There is hence a need to increase doctors' self-awareness and convince them to consider their own emotions as an important tool in medical treatment in general, and in pain medicine in particular. Medical training should include appropriate opportunities to learn about and manage the emotional impact of illness experiences and the healing process. ${ }^{32}$ It may even be that painful experiences and emotions experienced by doctors themselves may pave the path toward a healing understanding of patients' pain.

Third, we need a deeper insight into state and trait variables that underlie the substantial variability of placebo analgesia across individuals. For instance, optimism and resilience have a positive influence on the magnitude of pain reduction, ${ }^{33,34}$ whereas emotional lability ${ }^{35}$ and anxiety ${ }^{36-38}$ weaken the effect. One might say that an individual prone to positive expectations, who is likely to anticipate pain relief in a placebo treatment, shows a greater profit. In keeping with this finding, Wager et $\mathrm{al}^{39}$ were able to show that brain activity during the anticipation of pain with increased activity in the dorsolateral prefrontal cortex, orbitofrontal cortex, parietal cortex, and cerebellum best predicted individual differences in placebo analgesia, whereas reductions in pain-processing regions during the application of a placebo skin cream were not correlated with individual differences in analgesia. However, a majority of these studies relate to healthy populations, and their findings are not easily transferred to chronic pain patients characterized by personality traits such as harm avoidance, which predisposes them to anxiety. ${ }^{40,41}$ To be able to personalize placebo analgesia, a greater understanding is required of the subtle influence of situational and personal variables on the creation of positive expectations in the prefrontal cortex in different pain populations.

Fourth, the placebo analgesic interventions that work best must be identified. There is growing evidence that the more impressive interventions are more powerful than their less impressive equivalents. ${ }^{4}$ Thus, sham acupuncture and sham surgery are more effective than oral placebos. ${ }^{42}$ Recent findings even lend support to the notion that pain reduction due to acupuncture is mainly explained by the placebo response, as sham acupuncture and acupuncture are equally effective in the treatment of lower back pain and osteoarthritis of the 
knee. ${ }^{43}$ Placebo analgesia is effective because of the treatment's symbolic import: "a symbol is an energy evoking, and directing agent". ${ }^{44}$ The more the color, sound, odor, taste, and haptics of a placebo evoke an expectation of pain relief, the more likely it is to reduce pain. This may also apply to the placebo response initiated by a verum. A systematic review found that placebo responses could account for $62 \%$ of the benefit of drugs used to treat peripheral neuropathic pain. ${ }^{45}$ If the placebo effect is mediated and modulated by different neurotransmitters such as opioids and cannabinoids, the complex interplay between, for example, an opioid analgesic and the opioidergic neurotransmission of placebo response is unclear. Do these analgesic effects combine in an additive or an interfering manner? ${ }^{4}$ An initial study found a relevant additive effect on clinical outcome, including expectancy modulated activity in the frontal cortex, with a separable time course from drug effects. ${ }^{46}$ However, it is important not to use placebo analgesia as a means to justify any and every bizarre healing ritual. ${ }^{6}$ Placebo analgesia walks a constant tightrope between initiating pain relief via healing expectations and the corresponding physiologic response, and initiating pain via counterproductive expectations. ${ }^{6}$

The earlier questions indicate that more research is urgently needed to fully explore the potential of placebo analgesia. For reasons previously discussed, the volume of funding provided for research into specific analgesics is not comparable with the funding for placebo analgesia. But perhaps, the time has come to start thinking in new terms. "Value should always be defined around the customer, and in a well-functioning health care system, the creation of value for patients should determine the rewards for all other actors in the system". ${ }^{47}$ An important step in this direction would be the substantial funding of placebo analgesia research by the pharmaceutical industry. Ultimately, placebo analgesia reminds us of the sometimes forgotten lesson that the doctor-patient relationship is at the center of all pain medicine: "Sometimes simply being silently present with a patient may be the most meaningful kind of care", ${ }^{48}$

\section{Disclosure}

The author reports no conflicts of interest in this work.

\section{References}

1. Vase L, Riley JL 3rd, Price DD. A comparison of placebo effects in clinical analgesic trials versus studies of placebo analgesia. Pain. 2002;99(3):443-452.

2. Vase L, Petersen GL, Riley JL 3rd, Price DD. Factors contributing to large analgesic effects in placebo mechanism studies conducted between 2002 and 2007. Pain. 2009;145(1-2):36-44.
3. Hróbjartsson A, Gøtzsche PC. Placebo interventions for all clinical conditions. Cochrane Database Syst Rev. 2010;(1):CD003974.

4. Colloca L, Flaten MA, Meissner K, editors. Placebo and Pain: From Bench to Bedside. Amsterdam: Elsevier; 2013.

5. Brody H. Placebos and the Philosophy of Medicine: Clinical, Conceptual, and Ethical Issues. Chicago, IL: University of Chicago Press; 1980.

6. Benedetti F. Placebo and the new physiology of the doctor-patient relationship. Physiol Rev. 2013;93(3):1207-1246.

7. Krummenacher P, Candia V, Folkers G, Schedlowski M, Schönbächler G. Prefrontal cortex modulates placebo analgesia. Pain. 2010;148(3):368-374.

8. Eippert F, Bingel U, Schoell ED, et al. Activation of the opioidergic descending pain control system underlies placebo analgesia. Neuron. 2009;63(4):533-543.

9. Eippert F, Finsterbusch J, Bingel U, Büchel C. Direct evidence for spinal cord involvement in placebo analgesia. Science. 2009;326(5951):404.

10. Moerman DE. Meaningful placebos--controlling the uncontrollable. $N$ Engl J Med. 2011;365(2):171-172.

11. Annoni M, Miller FG. Placebo effects and the ethics of therapeutic communication: a pragmatic perspective. Kennedy Inst Ethics $J$. 2016;26(1):79-103.

12. Hippocrates of Kos. The Oath. Cambridge, MA: Loeb Classical Library, Harvard University Press; 1923.

13. Kant I, Paton HJ. Groundwork of the Metaphysic of Morals. Translated and analysed by Paton HJ. New York, NY: Harper \& Row; 1964.

14. Hull SC, Colloca L, Avins A, et al. Patients' attitudes about the use of placebo treatments: telephone survey. BMJ. 2013;347:f3757.

15. Kaptchuk TJ, Friedlander E, Kelley JM, et al. Placebos without deception: a randomized controlled trial in irritable bowel syndrome. PLoS One. 2010;5(12):e15591.

16. Schatman ME. A glimmer of hope in American pain medicine? J Pain Res. 2016;9:509-513.

17. Taylor ML. The impact of the "business" of pain medicine on patient care. Pain Med. 2011;12(5):763-772.

18. Niethard F, Malzahn J, Schäfer T. Endoprothetik und Wirbeslsäuleneingriffe: Uneinheitliches Versorgungsgeschehen [Arthroplasty and spinal procedures: uneven supply done]. Dtsch Arztebl. 2013;110(27-28):A1362/B-1197/C-1181. German.

19. Kulich R, Loeser JD. The business of pain medicine: the present mirrors antiquity. Pain Med. 2011;12(7):1063-1075.

20. Stamatakis E, Weiler R, Ioannidis JP. Undue industry influences that distort healthcare research, strategy, expenditure and practice: a review. Eur J Clin Invest. 2013;43(5):469-475.

21. Agrawal S, Brown D. The Physician Payments Sunshine Act--two years of the Open Payments Program. N Engl J Med. 2016;374(10):906-909.

22. Becker K, Brunner BK, Wormer V. Versteckte Zuwendungen - Ärzte, Pharmafirmen und das große Geld [Hidden donations - doctors, drug companies and big money]. Süddeutsche Zeitung. 2016 July 20. German.

23. Crow R, Gage H, Hampson S, Hart J, Kimber A, Thomas H. The role of expectancies in the placebo effect and their use in the delivery of health care: a systematic review. Health Technol Assess. 1999;3(3):1-96.

24. Ulrich RS. View through a window may influence recovery from surgery. Science. 1984;224(4647):420-421.

25. Walch JM, Rabin BS, Day R, Williams JN, Choi K, Kang JD. The effect of sunlight on postoperative analgesic medication use: a prospective study of patients undergoing spinal surgery. Psychosom Med. 2005;67(1):156-163.

26. Shapiro AK, Shapiro E. The Powerful Placebo: From Ancient Priest to Modern Physician. Baltimore, MD: Johns Hopkins University Press; 1997.

27. Gryll SL, Katahn M. Situational factors contributing to the placebos effect. Psychopharmacology (Berl). 1978;57(3):253-261.

28. Kaptchuk TJ, Kelley JM, Conboy LA, et al. Components of placebo effect: randomised controlled trial in patients with irritable bowel syndrome. BMJ. 2008;336(7651):999-1003.

29. Kelley JM, Lembo AJ, Ablon JS, et al. Patient and practitioner influences on the placebo effect in irritable bowel syndrome. Psychosom Med. 2009;71(7):789-797. 
30. Matsumoto DR, Frank MG, Hwang HS. Nonverbal Communication Science and Applications. Los Angeles, CA: Sage; 2013.

31. Shapiro J. Perspective: does medical education promote professional alexithymia? A call for attending to the emotions of patients and self in medical training. Acad Med. 2011;86(3):326-332.

32. Sternlieb JL. A guide to introducing and integrating reflective practices in medical education. Int J Psychiatry Med. 2015;49(1):95-105.

33. Morton DL, Watson A, El-Deredy W, Jones AK. Reproducibility of placebo analgesia: effect of dispositional optimism. Pain. 2009;146(1-2):194-198.

34. Geers AL, Kosbab K, Helfer SG, Weiland PE, Wellman JA. Further evidence for individual differences in placebo responding: an interactionist perspective. J Psychosom Res. 2007;62(5):563-570.

35. Peciña M, Azhar H, Love TM, et al. Personality trait predictors of placebo analgesia and neurobiological correlates. Neuropsychopharmacology. 2013;38(4):639-646.

36. Lyby PS, Aslaksen PM, Flaten MA. Is fear of pain related to placebo analgesia? J Psychosom Res. 2010;68(4):369-377.

37. Lyby PS, Forsberg JT, Asli O, Flaten MA. Induced fear reduces the effectiveness of a placebo intervention on pain. Pain. 2012;153(5):1114-1121.

38. Aslaksen PM, Lyby PS. Fear of pain potentiates nocebo hyperalgesia. J Pain Res. 2015;8:703-710.

39. Wager TD, Atlas LY, Leotti LA, Rilling JK. Predicting individual differences in placebo analgesia: contributions of brain activity during anticipation and pain experience. J Neurosci. 2011;31(2):439-452.
40. Conrad R, Schilling G, Bausch C, et al. Temperament and character personality profiles and personality disorders in chronic pain patients. Pain. 2007;133(1-3):197-209.

41. Conrad R, Wegener I, Geiser F, Kleiman A. Temperament, character, and personality disorders in chronic pain. Curr Pain Headache Rep. 2013;17(3):318.

42. Kaptchuk TJ, Stason WB, Davis RB, et al. Sham device v inert pill: randomised controlled trial of two placebo treatments. $B M J$. 2006;332(7538):391-397.

43. Cummings M. Modellvorhaben Akupunktur-a summary of the ART, ARC and GERAC trials. Acupunct Med. 2009;27(1):26-30.

44. Campbell J. The Flight of the Wild Gander: Explorations in the Mythological Dimension: Selected Essays, 1944-1968. Novato, CA: New World Library; 2002.

45. Häuser W, Bartram-Wunn E, Bartram C, Reinecke H, Tölle T. Systematic review: placebo response in drug trials of fibromyalgia syndrome and painful peripheral diabetic neuropathy-magnitude and patient-related predictors. Pain. 2011;152(8):1709-1717.

46. Atlas LY, Whittington RA, Lindquist MA, Wielgosz J, Sonty N, Wager TD. Dissociable influences of opiates and expectations on pain. $J \mathrm{Neu}-$ rosci. 2012;32(23):8053-8064.

47. Porter ME. What is value in health care? N Engl J Med. 2010; 363(26):2477-2481

48. Bazari H. Gratitude, memories, and meaning in medicine. $N$ Engl $J$ Med. 2010;363(23):2187-2189.

Dove Medical Press encourages responsible, free and frank academic debate. The content of the Journal of Pain Research 'Editorial' section does not necessarily represent the views of Dove Medical Press, its officers, agents, employees, related entities or the Journal of Pain Research editors. While all reasonable steps have been taken to confirm the content of each Editorial, Dove Medical Press accepts no liability in respect of the content of any Editorial, nor is it responsible for the content and accuracy of any Editorial.

\section{Journal of Pain Research}

\section{Publish your work in this journal}

The Journal of Pain Research is an international, peer reviewed, open access, online journal that welcomes laboratory and clinical findings in the fields of pain research and the prevention and management of pain. Original research, reviews, symposium reports, hypothesis formation and commentaries are all considered for publication.

\section{Dovepress}

The manuscript management system is completely online and includes a very quick and fair peer-review system, which is all easy to use. Visit http://www.dovepress.com/testimonials.php to read real quotes from published authors. 